\title{
Benthic habitat selection in juvenile European eel Anguilla anguilla : implications for coastal habitat management and restoration
}

Christoffersen, M.; Svendsen, Jon Christian; Kuhn, J. A.; Nielsen, A.; Martjanova, A.; Støttrup, Josianne Gatt

Published in:

Journal of Fish Biology

Link to article, DOI:

$10.1111 / \mathrm{jfb} .13807$

Publication date:

2018

Document Version

Peer reviewed version

Link back to DTU Orbit

Citation (APA):

Christoffersen, M., Svendsen, J. C., Kuhn, J. A., Nielsen, A., Martjanova, A., \& Støttrup, J. G. (2018). Benthic habitat selection in juvenile European eel Anguilla anguilla : implications for coastal habitat management and restoration. Journal of Fish Biology, 93(5), 996-999. https://doi.org/10.1111/jfb.13807

\section{General rights}

Copyright and moral rights for the publications made accessible in the public portal are retained by the authors and/or other copyright owners and it is a condition of accessing publications that users recognise and abide by the legal requirements associated with these rights.

- Users may download and print one copy of any publication from the public portal for the purpose of private study or research.

- You may not further distribute the material or use it for any profit-making activity or commercial gain

- You may freely distribute the URL identifying the publication in the public portal 


\title{
Benthic habitat selection in juvenile European eel Anguilla anguilla: implications for coastal habitat management and restoration
}

\author{
M. CHRISTOFFERSEN, J. C. SVENDSEN, J. A. KUHN, A. NIELSEN, A.
}

MARTJANOVA, J. G. STØTTRUP

Technical University of Denmark, National Institute of Aquatic Resources (DTU Aqua), DK2800 Lyngby, Denmark

\section{Correspondence}

M. Christoffersen, Technical University of Denmark, National Institute of Aquatic Resources (DTU Aqua), DK-2800 Lyngby, Denmark

Email: maoc@aqua.dtu.dk

\begin{abstract}
The critically endangered European eel Anguilla anguilla is dependent on suitable habitat qualities over a vast geographic area. Even though a significant proportion of the population never enters fresh water, the preferred benthic habitat is largely unknown in the marine environment. Examining substratum selection in A. anguilla reveals that elvers prefer coarse gravel, suggesting that conservation efforts may benefit from targeting this type of substratum in marine coastal areas.
\end{abstract}

This article has been accepted for publication in the Journal of Fish Biology and undergone full peer review but has not been through the copyediting, typesetting, pagination and proofreading process, which may lead to differences between this version and the Version of Record. Please cite this article as doi: 10.1111/jfb.13807

This article is protected by copyright. All rights reserved. 


\section{KEYWORDS}

Anguilla anguilla, coastal management, elvers, European eel, habitat selection, marine sediment

Marine habitat selection and burrowing behaviours by Anguilla anguilla L. 1758 elvers were examined in the laboratory. Specifically, it was hypothesized that A. anguilla actively selects between four different marine substrata. Previous studies, mostly conducted in the freshwater environment, have indicated that $A$. anguilla selects a diversity of habitats that are usually dependent on the body size (stage) of the eels (Westerberg et al., 1993; Laffaille et al., 2003; Pedersen, 2009). During the daytime and during winter, yellow-stage A. anguilla often shelter in sand, mud, fine gravel or in the interstitial spaces between coarse gravel and cobble to avoid predation (Tomie et al., 2017). In contrast, substratum preference of A. anguilla elvers is largely unknown. The elver life stage follows metamorphosis of the glass eels, resulting in a miniature version of the adult $A$. anguilla. Knowledge on marine benthic habitat selection in A. anguilla elvers is an important step towards understanding the behaviour and ecology of this life stage, which may contribute to coastal management and the preservation of this species.

Many marine coastal habitats are degraded by anthropogenic activities including dredge fisheries, e.g., trawling (Jennings \& Kaiser, 1998; Freese et al., 1999; Gage et al., 2005), extractions of marine sand and gravel in coastal areas (de Groot 1986, 1996, Desprez 2000; ICES 2015), or affected by frequent and severe occurrences of hypoxia (Schmidtko et al., 2017; Breitburg et al., 2018), phytoplankton blooms (Diaz \& Rosenberg, 2008; Chapman, 2016) and pollution (Sühring et al., 2016; Vince \& Hardesty, 2016). Multiple concurrent pressures have altered the type and spatial distribution of vegetation in coastal areas as well as resulting in changes in sediment type (ICES, 2015).

This article is protected by copyright. All rights reserved. 
In mid-June 2015 , elvers $\left(n=129\right.$, mean \pm SD total body length $\left.\left(L_{\mathrm{T}}\right)=10.8 \pm 1.2 \mathrm{~cm}\right)$ were collected in a trap situated in the Hellebækken Brook $\left(56^{\circ} 03^{\prime} 54.53^{\prime \prime} \mathrm{N} ; 12^{\circ} 33^{\prime} 14.78^{\prime \prime}\right.$ E) in north-eastern Denmark. The trap was situated $2 \mathrm{~m}$ from the sea and emptied every $48 \mathrm{~h}$. Therefore, elvers were in fresh water for a maximum of $48 \mathrm{~h}$ before they were collected. Fish were kept in a flow-through holding tank $\left(T=17 \pm 1^{\circ} \mathrm{C}\right.$; salinity $14 \pm 1$; photoperiod $\left.8 \mathrm{~L}: 16 \mathrm{D}\right)$ and fed dry pellets every second day for 3 weeks prior to experimentation. Following Carl et al. (2008), two identical experimental tanks $(75 \times 15 \times 40 \mathrm{~cm}, \mathrm{~L} \times \mathrm{W} \times \mathrm{D})$ were each divided into four equal squares $(18.75 \times 15 \times 40 \mathrm{~cm}, \mathrm{~L} \times \mathrm{W} \times \mathrm{D})$, separated by $15 \mathrm{~cm}$ high Plexiglas walls. A basket made of fine plastic mesh $(18.5 \times 14.75 \times 39.75 \mathrm{~cm}, \mathrm{~L} \times \mathrm{W} \times \mathrm{D})$ was placed in each of the four squares.

Four different substrata were prepared for the experiment, one substratum in each mesh basket. Substrata were retrieved at the end of each trial by lifting the basket to examine for the presence of elvers. The Plexiglas separation and the top of the substratum were level, ensuring that the substratum separation did not interfere with substratum selection.

Tested substrata included fine gravel (FG; $\varnothing=8-12 \mathrm{~mm}$ ), medium gravel (MG; $\varnothing=$ $12-32 \mathrm{~mm}$ ), large gravel (LG; $\varnothing=32-64 \mathrm{~mm})$ and sand $(\varnothing=0.25-0.50 \mathrm{~mm})$ combined with vegetation (SV). Sand was collected from a nearby beach, while the other substrata (FG, MG and LG) came from a commercial gravel supplier. As with previous studies (Carl et al., 2008; Jepsen et al., 2008), vegetation was simulated using strands of plastic ribbon, imitating eelgrass Zostera marina. In each SV square, $c .150$ strands $(25 \mathrm{~cm}$ high) simulated an eelgrass meadow, with height and density similar to natural habitats (Short et al., 1995). Water variables in the two experimental tanks were the same as in the holding tank.

Elvers were transferred to the experimental tanks without air contact (Poulsen et al., 2010, 2012). Preliminary experiments indicated that elvers spent 30 min searching for 
favourable substrata after the transfer. Elvers were therefore acclimated for 30 min prior to data collection similar to previous studies (Poulsen et al., 2010, 2012).

Data collection included 12 trials (replicates) in total, with elver groups consisting of 913 individuals. Individuals were introduced simultaneously to the tank to avoid any confounding influence of introduction order (Svendsen et al., 2003) and were distributed evenly over the four squares. After 30 min acclimation, data collection comprised observing the individual habitat use every $30 \mathrm{~min}$ for $2 \mathrm{~h}$ (i.e. five measures of habitat selection after acclimation (at $0,30,60,90,120 \mathrm{~min}$ ). For each individual, habitat use was divided into three categories: Category 1, elvers with $>80 \%$ of their body covered by the substratum; Category 2, elvers with their body $\leq 80 \%$ covered by the substratum; Category 3 , elvers swimming in the water column. The $80 \%$ threshold was arbitrarily chosen but appeared to be a useful measure to separate different behaviours. After data collection, all A. anguilla were retrieved alive from the experimental tanks and returned to the brook. No fish were used more than once.

To analyse the habitat preference of elvers, $X_{i j}$ was the observed number of elvers in habitat $i$ in the $j$ th trial $i=\mathrm{FG}, \mathrm{MG}, \mathrm{LG}, \mathrm{SV}$ and $j=1, \ldots, 12$. The simple multinomial model states that the vector: $x_{j} \sim$ multinomial $\left(N_{j}, P_{j}\right)$, where $N_{j}$ is the number of elvers in the $j$ th trial and $P_{j}=\left(p_{\mathrm{FG} j}, p_{\mathrm{MG} j}, p_{\mathrm{LG} j}, p_{\mathrm{SV} j}\right)$ is a probability vector describing the preferences for each substratum in the $j$ th trial. However, the individual trials revealed that a simple multinomial model, with a common $P$ vector for all trials $\left(P_{j}=P\right)$, was insufficient due to over dispersion. To account for this, the model was extended such that $P_{j}=q_{j}\left(\Sigma q_{j}\right)^{-1}$, where $q_{i j}=\exp \left(\alpha_{i}+z_{i j}\right)$. Here, $\alpha_{i}$ is the unbounded parameters describing the common (across trials) part of the probability vector and $z_{i j}$ are mean zero random deviations describing the variation between trials $z_{i j} \sim N\left(0, \sigma^{2}\right)$. This allows the model to capture the variation between the individual trials, but at the same time gives an estimate of the overall preference across experiments. 
To analyse behaviour across time, we compared the distribution of $A$. anguilla elvers > $80 \%$ covered in sediment, $\leq 80 \%$ covered in sediment, or swimming at the five different observation times (i.e. 0, 30, 60, 90, 120 min after acclimation). The analysis was performed using a $\chi^{2}$-test, but as it was not possible to observe the trend per trial, so for this analysis, data from all 12 trials were summed.

The results showed that, on average, $44 \%, 30 \%, 14 \%$ and $12 \%$ of the elvers were found in MG, LG, SV and FG, respectively (Figure 1). The hypothesis that the elvers selected habitats randomly was rejected (likelihood ratio test $P<0.001$ ). Instead, a hypothesis that only two levels of preference existed, one for habitats LG and MG (both with a probability = $37 \pm 2 \%$ ) and one for habitats SV and FG (both with a probability $=13 \pm 2 \%$ ), was accepted (likelihood ratio test $P>0.05$ ). Results indicated that elvers exhibited an almost three-times greater preference for LG compared with FG and SV.

No significant difference was found in the distribution of $A$. anguilla $>80 \%$ covered, $\leq$ $80 \%$ covered or swimming between the five different observation times (Pearson's $\chi^{2}$-test, $\chi^{2}$ $=11.3, P>0.05)$. This showed that behaviours did not change over time, indicating that the acclimation time used in the present study (30 min) was adequate (Table 1).

To the authors' best knowledge, this is the first study to document habitat selection and burrowing behaviour by A. anguilla elvers in a marine setting. The results show that elvers prefer coarse benthic habitats $(\varnothing=12-64 \mathrm{~mm})$. Most studies on A. anguilla habitat selection and substratum preference, have only investigated the freshwater environment (Daverat \& Tomas, 2006; Pedersen, 2009). However, Nyman (1972) documented substratum preference of young yellow A. anguilla $\left(L_{\mathrm{T}}=13-37 \mathrm{~cm}\right)$ in a coastal environment. He found that in cold $\left(5-8^{\circ} \mathrm{C}\right)$ water, A. anguilla is inactive and hidden in mud, protected from predators. In warmer $\left(>9^{\circ} \mathrm{C}\right)$ water, A. anguilla migrates from mud to rocky areas and more A. anguilla are swimming freely. Importantly, at temperatures comparable with the present study (16-18 
${ }^{\circ} \mathrm{C}$ ), sheltering individuals appeared to favour rocks over sand (Nyman, 1972), which is in accordance with our observations.

The availability of shelters between tree roots and similar crevices in streams (Pedersen, 2009) and in vegetated areas in the coastal zone, partly explains the carrying capacity for A. anguilla elvers in these habitats (Westerberg et al., 1993). Field observations in Danish coastal gravel areas have also revealed high densities of elvers when stones are upturned (M. Christoffersen, unpubl. data). Along with the observed preference for coarse gravel (MG and LG) in the present study, this indicates that $A$. anguilla elvers prefer spatially complex habitats. Many biological factors (e.g. presence of food and predators) were excluded in the present experiment, indicating that the substratum selection of elvers was determined mainly by the physical attributes of available substrata. The gravel substratum provides shelter without the need for burrowing and is therefore a quickly available refuge. An elevated shelter availability, provided by coarse gravel, might increase the carrying capacity for A. anguilla elvers in the marine environment. This would resemble the observations in freshwater environments and in vegetated areas in the coastal zone (Westerberg et al., 1993; Laffaille et al., 2003; Pedersen, 2009).

The body form and behaviour of anguillids suggests that they are adapted for using many different types of shelter, including the need for burrowing (Gans, 1975). Indeed, anguillids inhabit a variety of habitats (Tesch, 2003). In the marine environment, Tomie et al. (2017) found that yellow-stage American eels Anguilla rostrata (Lesueur 1817) (> $30 \mathrm{~cm}$ ) prefer mud substrata during most of the year, except in the winter periods $\left(<2^{\circ} \mathrm{C}\right)$ when preference shifts more towards cobble substrata. At lower temperatures, the metabolic rate of A. rostrata is depressed (Walsh et al., 1983) and perhaps this is part of the reason that anguillids in cold water seem to hide in cobble interstitial spaces, instead of actively burying. Moreover, elevated sheltering as well as reduced burying and swimming at low temperatures 
$\left(<2-8^{\circ} \mathrm{C}\right)$ could be responses to increased predation risk by homoeothermic predators that may have an advantage over heterothermic prey in cold water (Heggenes et al., 1993; Svendsen et al., 2004). The study by Tomie et al. (Tomie et al., 2017) was conducted on yellow eel and although no similar studies are available on elvers in the marine environment, burrowing behaviour may be similar in the different life stages. Burrowing in the SV substratum was not observed in the present study, but elvers could use the same burrowing behaviours in the medium (MG) and large (LG) gravel as observed by Tomie et al. (Tomie et al., 2013). The authors indicate that $A$. rostrata commonly burrow in soft-bottomed habitats, but also discuss a potential bias because the greater part of their study area consisted of soft bottom. Aoyama et al. (2005) suggested that Japanese eels Anguilla Japonica Temminck \& Schlegel 1846 construct mud burrows only when other more spatially complex habitats are unavailable and further suggested that A. japonica may not be morphologically adapted to perform well in burrows.

Many A. anguilla are estuarine-dependent (Tzeng et al., 2000) and a large proportion of glass-eel larvae end the journey from the Sargasso Sea in the coastal areas of northern Europe and never enter freshwater systems (Tsukamoto et al., 1998). Elvers of A. anguilla typically arrive in inner Danish waters in late spring when water temperatures and salinities resemble the experimental conditions used in the present study. Inner Danish waters and estuaries represent a transition area, between the brackish Baltic Sea and the more saline Kattegat and North Sea. The bottom salinity in inner Danish waters varies a lot, with salinities approaching 30 in the northern Kattegat region $\left(57_{\mathrm{o}} 30^{\prime} \mathrm{N} ; 11^{\circ} 00^{\prime} \mathrm{E}\right)$ and 10 in the Arkona Basin $\left(55^{\circ} 00^{\prime}\right.$ $\mathrm{N} ; 13^{\circ} 00^{\prime}$ E) (Zervoudaki et al., 2009). A salinity of 14 was chosen in the present study to simulate a typical estuarine system. As the elvers used in this experiment were collected in a trap (emptied every $48 \mathrm{~h}$ ) positioned about $2 \mathrm{~m}$ from where the Hellebækken Brook drains into the Kattegat and the elvers were acclimated for 3 weeks before beginning the 
experiments, we assume little or no effects from the transfer between salinities on the results of the experiments. Nevertheless, further studies are needed, but our results indicate that preservation of coarse marine substrata should be taken into consideration while planning future management initiatives and restoration projects. An elevated availability of marine coarse substrata is probably beneficial to the coastal population of A. anguilla elvers.

\section{ACKNOWLEDGEMENTS}

The Danish National Coastal Fisheries Management Programme and the Danish Agricultural Agency supported the present study. The authors thank the National Aquarium of Denmark (Den Blå Planet) and the zookeepers for access to the facilities and for taking care of the elvers. The authors also thank B. Persson from the Danish Nature Agency for collecting the elvers used in the experiment.

\section{REFERENCES}

Aoyama, J., Shinoda, A., Sasai, S., Miller, M. J. \& Tsukamoto, K. (2005). First observations of the burrows of Anguilla japonica. Journal of Fish Biology 67, 1534-1543.

Breitburg, D., Levin, L. A., Oschlies, A., Grégoire, M., Chavez, F. P., Conley, D. J., Garçon, V., Gilbert, D., Gutiérrez, D., Isensee, K., et al. (2018). Declining oxygen in the global ocean and coastal waters. Science 359, eaam7240.

Carl, J. D., Sparrevohn, C. R., Nicolajsen, H. \& St??ttrup, J. G. (2008). Substratum selection by juvenile flounder Platichthys flesus (L.): Effect of ephemeral filamentous macroalgae. Journal of Fish Biology 72, 2570-2578.

Chapman, P. M. (2016). Assessing and managing stressors in a changing marine

This article is protected by copyright. All rights reserved. 
environment. Marine Pollution Bulletin 124, 587-590.

Daverat, F. \& Tomas, J. (2006). Tactics and demographic attributes in the European eel Anguilla anguilla in the Gironde watershed, SW France. Marine Ecology Progress Series 307, 247-257.

Desprez, M. (2000). Physical and biological impact of marine aggregate extraction along the French coast of the Eastern English Channel: short and long-term post-dredging restoration. ICES Journal of Marine Science 57, 1428-1438.

Diaz, R. J. \& Rosenberg, R. (2008). Spreading Dead Zones and Consequences for Marine Ecosystems. Science 321, 926-929.

Freese, L., Auster, P. J., Heifetz, J. \& Wing, B. L. (1999). Effects of trawling on seafloor habitat and associated invertebrate taxa in the Gulf of Alaska. Marine Ecology Progress Series 182, 119-126.

Gage, J. D., Roberts, J. M., Hartley, J. P. \& Humphery, J. D. (2005). Potential impacts of deep-sea trawling on the benthic ecosystem along the northern European continental margin: a review. In American Fisheries Society Symposium 41: Benthic Habitats and the Effects of Fishing (Barnes, P. W. \& Thomas, J. P., eds), pp. 503-517. Bethesda, MD: AFS.

Gans, C. (1975). Tetrapod Limblessness: Evolution and Functional Corollaries. American Zoologist 15, 455-467, doi:10.2307/3882231.

Groot, S. J. de. (1986). Marine sand and gravel extraction in the North Atlantic and its potential environmental impact, with emphasis on the North Sea. Ocean Management 10, 21-36.

Groot, S. J. de. (1996). The physical impact of marine aggregate extraction in the North Sea. ICES Journal of Marine Science 53, 1051-1053.

Heggenes, J., Krog, O. M. W., Lindas, O. R. \& Dokk, J. G. (1993). Homeostatic behavioural 
responses in a changing environment: brown trout (Salmo trutta) become nocturnal during winter. Journal of Animal Ecology 62, 295-308.

ICES. (2015). Interim Report of the Working Group on the Effects of Extraction of Marine Sediments on the Marine Ecosystem (WGEXT). ICES CM 2016/SSGEPI:06. Available at http://ices.dk/sites/pub/Publication\%20Reports/Expert\%20Group\%20Report/SSGEPI/2 016/01\%20WGEXT\%20-

$\% 20$ Report $\% 20$ of $\% 20$ the $\% 20$ Working\%20Group $\% 20$ on $\% 20$ the $\% 20$ Effects $\% 20$ of $\% 20$ Extraction\%20of\%20Marine\%20Sediments\%20on\%20the\%20Marine\%20Ecosystem.p df

Jennings, S. \& Kaiser, M. J. (1998). The Effects of Fishing on Marine Ecosystems. Advances in Marine Biology 34, 201-352.

Jepsen, N., Christoffersen, M. \& Munksgaard, T. (2008). The level of predation used as an indicator of tagging/handling effects. Fisheries Management and Ecology 15, 365-368.

Laffaille, P., Feunteun, E., Baisez, A., Robinet, T., Acou, A., Legault, A. \& Lek, S. (2003). Spatial organisation of European eel (Anguilla anguilla L.) in a small catchment. Ecology of Freshwater Fish 12, 254-264.

Nyman, L. (1972). Some effects of temperature on eel (Anguilla) behaviour. Report of the Institute of Freshwater Research, Drottningholm 52, 90-102.

Pedersen, M. I. (2009). Does Stocking of Danish Lowland Streams with Elvers Increase European Eel Populations? In American Fisheries Society Symposium 58: Eels at the Edge - Science, Status and Conservation Concerns (Casselman, J. M. \& Cairns, D. K., eds), pp. 149-156. Bethesda, MD: AFS.

Poulsen, S. B., Svendsen, J. C., Jensen, L. F., Schulz, C., Jäger-Kleinicke, T. \& Schwarten, H. (2010). Effects of food deprivation on refuge use and dispersal in juvenile North Sea

This article is protected by copyright. All rights reserved. 
houting Coregonus oxyrinchus under experimental conditions. Journal of Fish Biology 77, 1702-1708.

Poulsen, S. B., Jensen, L. F., Schulz, C., Deacon, M., Meyer, K. E., Jäger-Kleinicke, T., Schwarten, H. \& Svendsen, J. C. (2012). Ontogenetic differentiation of swimming performance and behaviour in relation to habitat availability in the endangered North Sea houting (Coregonus oxyrinchus). Aquatic Living Resources 25, 241-249.

Schmidtko, S., Stramma, L. \& Visbeck, M. (2017). Decline in global oceanic oxygen content during the past five decades. Nature 542, 335-339.

Short, F. T., Burdick, D. M. \& Kaldy, J. E. (1995). Mesocosm experiments quantify the effects of eutrophication on eelgrass, Zostera marina. Limnology and Oceanography 40, 740-749.

Sühring, R., Busch, F., Fricke, N., Kötke, D., Wolschke, H. \& Ebinghaus, R. (2016). Distribution of brominated flame retardants and dechloranes between sediments and benthic fish - a comparison of a freshwater and marine habitat. Science of the Total Environment 542, 578-585.

Svendsen, J. C., Skov, J., Bildsoe, M. \& Steffensen, J. F. (2003). Intra-school positional preference and reduced tail beat frequency in trailing positions in schooling roach under experimental conditions. Journal of Fish Biology 62, 834-846.

Svendsen, J. C., Koed, A. \& Aarestrup, K. (2004). Factors influencing the spawning migration of female anadromous brown trout. Journal of Fish Biology 64, 528-540.

Tesch, F. W. (2003). The Eel, $3^{\text {rd }}$ edn. Oxford, UK: Blackwell Science Ltd.

Tomie, J. P. N., Cairns, D. K. \& Courtenay, S. C. (2013). How American eels Anguilla rostrata construct and respire in burrows. Aquatic Biology 19.

Tomie, J. P. N., Cairns, D. K., Hobbs, R. S., Desjardins, M., Fletcher, G. L. \& Courtenay, S. C. (2017). American eel (Anguilla rostrata) substrate selection for daytime refuge and

This article is protected by copyright. All rights reserved. 
winter thermal sanctuary. Marine and Freshwater Research 68, 95-105.

Tsukamoto, K., Nakai, I. \& Tesch, W. V. (1998). Do all freshwater eels migrate? Nature 396, $635-636$.

Tzeng, W. N., Wang, C. H., Wickstrom, H. \& Reizenstein, M. (2000). Occurrence of the semi-catadromous European eel Anguilla anguilla in the Baltic Sea. Marine Biology 137, 93-98.

Vince, J. \& Hardesty, B. D. (2016). Plastic pollution challenges in marine and coastal environments: from local to global governance. Restoration Ecology 25, 123-128.

Walsh, P. J., Foster, G. D. \& Moon, T. W. (1983). The Effects of Temperature on Metabolism of the American Eel Anguilla rostrata (LeSueur): Compensation in the http://www.ices.dk/sites/pub/CM\%20Doccuments/1993/M/1993_M5.pdf Westerberg, H., Haamer, J. \& Lagenfelt, I. (1993). A new method for sampling elvers in the Coastal zone. ICES CM1993/M:5. Available at www.ices.dk/sites/pub/CM\%20Doccuments/1993/M/1993_M5.pdf

Zervoudaki, S., Nielsen, T. G. \& Carstensen, J. (2009). Seasonal succession and composition of the zooplankton community along an eutrophication and salinity gradient exemplified by Danish waters. Journal of Plankton Research 31, 1475-1492.

Figure 1. Mean $( \pm 95 \% \mathrm{Cl}$ ) probability of Anguilla anguilla $(n=129)$ found in four different substrata: large gravel (LG; $\varnothing=32-64 \mathrm{~mm}$ ), medium gravel (MG; $\varnothing=12-32 \mathrm{~mm}$ ), fine gravel (FG; $\varnothing=8-12 \mathrm{~mm}$ ) and sand $(\varnothing=0.25-0.50 \mathrm{~mm}$ ) combined with vegetation (SV).

This article is protected by copyright. All rights reserved. 


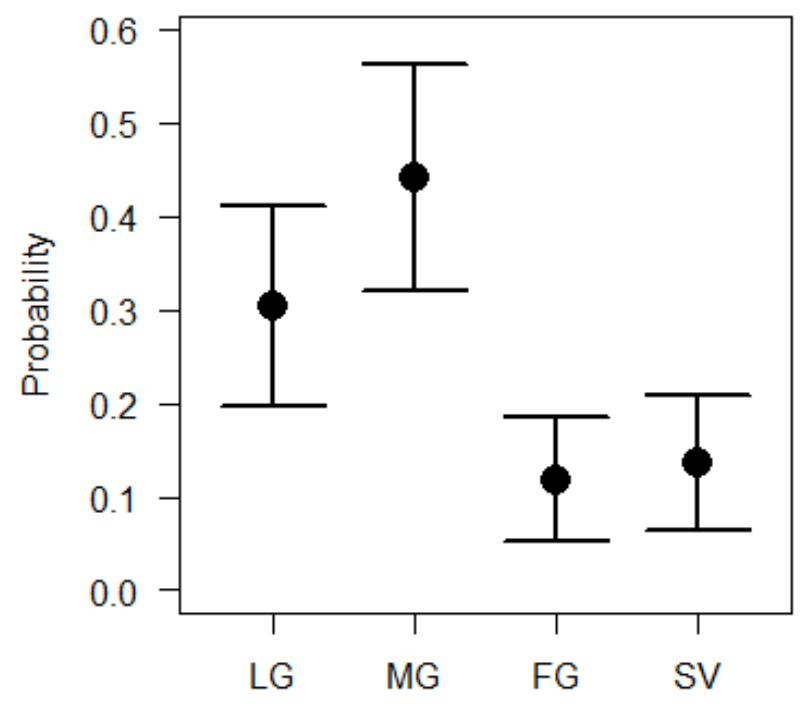

Table 1. Number of Anguilla anguilla elvers with different behaviours observed every 30 min until the end of experiment (120 $\mathrm{min})$

\begin{tabular}{|c|c|c|c|}
\hline & \multicolumn{2}{|c|}{ Coverage } & \multirow[b]{2}{*}{$\begin{array}{c}\text { Swimming } \\
\text { (n) }\end{array}$} \\
\hline $\begin{array}{l}\text { Observation } \\
\text { (min) }\end{array}$ & $\begin{array}{c}>80 \% \\
(n)\end{array}$ & $\begin{array}{c}\leq 80 \% \\
(n)\end{array}$ & \\
\hline 0 & $115^{+}$ & 7 & 7 \\
\hline 30 & $108+$ & 10 & 11 \\
\hline 60 & $103+$ & 19 & 7 \\
\hline 90 & $112+$ & 11 & 6 \\
\hline 120 & 111 & 14 & 4 \\
\hline
\end{tabular}

†Elvers that were $>80 \%$ covered could not be registred before the end of the experiement; calculated from; $n=129-\Sigma(\leq 80 \%+$ swimming $)$.

This article is protected by copyright. All rights reserved. 